\title{
Finite element modeling of the dynamic response of a composite reinforced concrete bridge for structural health monitoring
}

\author{
V. Zanjani Zadeh $\cdot$ A. Patnaik
}

Received: 5 July 2013/Accepted: 28 April 2014/Published online: 16 May 2014

(c) The Author(s) 2014. This article is published with open access at Springerlink.com

\begin{abstract}
This paper describes three-dimensional (3D) finite element (FE) modeling of a composite steel stinger supported reinforced concrete (RC) deck highway bridge subjected to moving truck loads. FE models were validated using test data that were generated elsewhere for structural health monitoring. The FE models were established using a commercial FE analysis package called ABAQUS/standard. The case study bridge was discretized to a combination of shell and solid elements which represent the deck and piers, respectively. Numerous constrain interactions were defined to make the model suitable to obtain accurate results. Moving loads induced by two standard AASHTO trucks were developed through a specific load-time history, applied on 35 nodes on the superstructure. To study the dynamic behavior of the bridge under a moving load, a modal analysis followed by an implicit dynamic analysis was carried out. Acceptable agreement was found between the field measurements and FE simulation. Most concerned dynamic response was strains at different locations in bridge girders and columns, because it is the only critical parameter that can be measured with confidence during SHM at site. The range of strains determined in analysis was reasonably close to the measured strains at the site of the study bridge. Several parameters including damping, truck weight and speed, and material properties were
\end{abstract}

\section{Zanjani Zadeh}

Department of Civil, Construction and Environmental

Engineering, North Carolina State University,

Campus Box 7908, Raleigh, NC 27695-7908, USA

e-mail: vzanjan@ncsu.edu

A. Patnaik $(\square)$

Department of Civil Engineering, The University of Akron,

Akron, OH 44325, USA

e-mail: patnaik@uakron.edu studied. Truck speed had the highest effect on strain response of both girders and columns.

Keywords Structural health monitoring - Finite element modeling · Dynamic behavior - Bridge - Moving loads . Truck weight · Truck speed · Damping · Material properties

\section{Introduction}

Bridges deteriorate over time like any other structures. The causes for such deterioration could be chemical attack, overloading, environmental effects, corrosion of steel reinforcement, and quality of maintenance. Hence, they require health monitoring and structural evaluation periodically to identify the structural deficiencies at an early stage, as well as verifying the efficacy of repair or rehabilitation procedures (Eshghi and Zanjanizadeh 2008).

Structural health monitoring (SHM) of bridges has emerged as an active research area in recent years. In general, past research on SHM can be categorized into two main classes. The first category consisted of FE or analytical modeling of bridges and/or bridge-vehicles interaction, which was carried out to perform moving load analysis and evaluation of bridge decks (Yin et al. 2010a, b; Kwasiewski et al. 2006; Kwasniewskia et al. 2006; Bu et al. 2006; Huang et al. 2006; Deng et al. 2010; Li et al. 2008; Yang et al. 1999; Zhang et al. 2008; Cai et al. 2007; Chiewanichakorn et al. 2007, 2010a, b; Cheng et al. 1999; Aktan et al. 1998). The second category is made up of recent developments in electronic data storage and computer data acquisition. Experimental methods such as wired or wireless sensors network systems were utilized mostly on superstructure to use in SHM (Farhey 2006; Wang et al. 
2007; Lynch 2007; Kim et al. 2007; Cho et al. 2010; Stajano et al. 2010; Yun and Min 2011).

Data acquisitions via conventional wired sensor system have high installation and maintenance cost (Lynch et al. 2003). In addition, wireless sensors are yet to be proven to be more reliable than conventional sensors. In particular, those with academic origin which were designed for laboratory conditions are required to be evaluated in real life scenarios.

Generally, most of the existing research focused on bridge deck and girders, and there appears to be a lack of study on condition assessment of bridge columns as part of whole structure despite their vulnerability to corrosion (Tonias and Zhao 2012), and susceptibility to vehicle collisions, which can influence the entire structure (ElTawil et al. 2005). However, because axial stiffness of the columns is several orders of magnitude greater than the flexural stiffness of the deck slabs and girders, changes in the vibration characteristics of the deck slab or girders do not adequately represent column deterioration. Furthermore, the deterioration of slabs is more of a material issue than a structural one (Ganapuram et al. 2012), and superstructure (slab and girders) are generally structurally stronger than required. Figure 1 exhibits a bridge structure (I-74, I-275 intersection in Cincinnati, OH, USA) that highlights this point. A locomotive engine uprooted two of the three columns, causing the bent cap to detach from the girders. Nevertheless, the deck slab and the girders were able to support its self-weight over two spans because of the reinforcement continuity in the deck. Similarly, the consequential collision and/or harsh environmental effects can cause deterioration of columns, by spalling and corrosion of the exposed steel reinforcing bars (Eshghi and Zanjanizadeh 2007). This problem is common in the piers that are situated under a leaking joint or in the splash zone

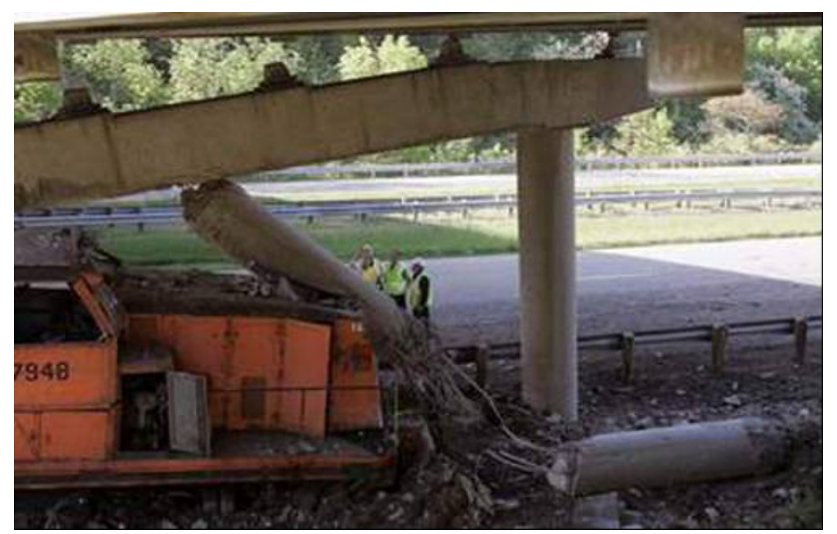

Fig. 1 Detached cap from girders due to a railroad locomotive collision on I-74 at I-275 intersection in Cincinnati, $\mathrm{OH}$ (shoulder piers). Figure 2 shows a spalled cover in a bridge column in Howe Ave., Akron, OH, USA.

This research consists of investigation of methodology for full-scale FE modeling of a bridge subjected to prescribed moving truck loads using a commercial package called ABAQUS/standard. Moving load induced by two standard AASHTO trucks was developed through a loadtime history that was applied on 35 nodes on the bridge deck. Modal and implicit dynamic analyses were carried out to study the dynamic behavior of bridges under moving load. The results of FE analysis were validated with data collected in SHM field tests conducted on this bridge through wired sensor network by another research group (Farhey 2006). Additionally, the influences of several parameters, such as variations in truck loads and speeds, structural damping ratios of the bridge, and the possible variations in material mechanical properties of concrete on the dynamic response of bridges, were investigated using FE modeling.

\section{The bridge geometry and structural characteristics}

An Ohio bridge, Westbound Ronald Reagan cross-country highway (SR126), HAM-126-0881, over Hamilton Avenue (Route 4), was selected for computer modeling. There are almost two identical and structurally separate bridges over Hamilton Avenue (approximate address 7255 U.S. 127, Mount Healthy). The bridge in the south part was selected and studied in this research. In Fig. 3, a picture of the

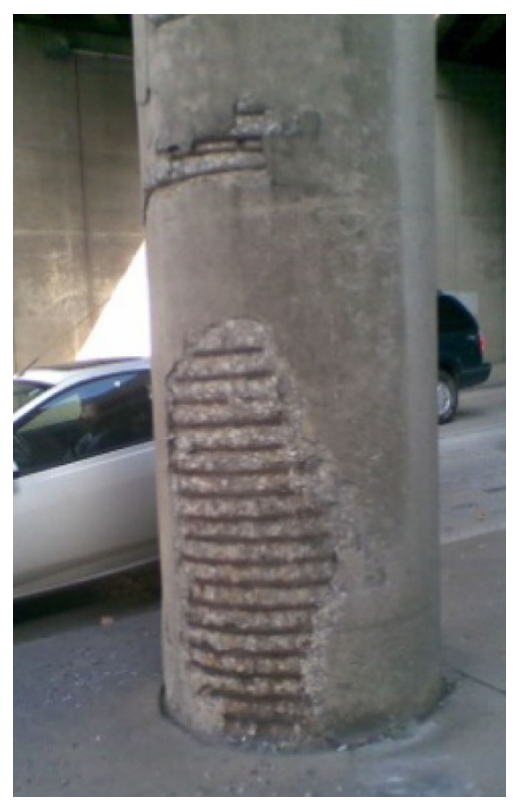

Fig. 2 Bridge column, Howe Ave., Akron, OH, USA 


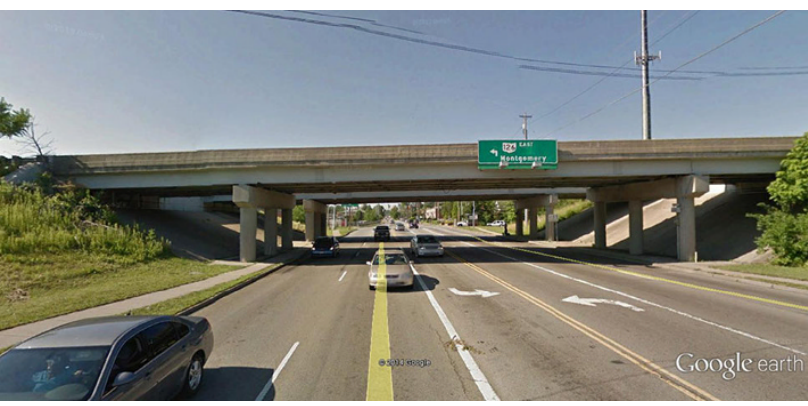

Fig. 3 South look of the study bridge (Google Earth image reproduced under "Fair Use" condition)

Table 1 Characteristics of the bridge (FHWA 2008)

\begin{tabular}{|c|c|c|c|}
\hline Length & Spans & Roadway width & Girder steel \\
\hline $170 \mathrm{ft}$ & $\begin{array}{l}40.21 \mathrm{ft}, 88.47 \mathrm{ft}, \\
40.3 \mathrm{ft}\end{array}$ & $40 \mathrm{ft}$ & ASTM A-36 \\
\hline $\begin{array}{l}\text { Girder } \\
\text { spacing }\end{array}$ & Deck thickness & $\begin{array}{c}\text { Abutment } \\
\text { support }\end{array}$ & $\begin{array}{l}\text { Concrete } \\
\text { strength } f_{\mathrm{c}}^{\prime}\end{array}$ \\
\hline $9.75 \mathrm{ft}$ & $8.75 \mathrm{in.}$ & Integral & $\begin{array}{l}4,500 \mathrm{psi} \\
(28 \text { days })\end{array}$ \\
\hline \multicolumn{2}{|c|}{ Capacity design } & $\begin{array}{l}\text { Reinforcement } \\
\text { steel }\end{array}$ & Pier support \\
\hline \multicolumn{2}{|c|}{$\begin{array}{l}\text { End spans non-composite, } \\
\text { middle span composite }\end{array}$} & Grade 60 & $\begin{array}{l}\text { Elastomeric } \\
\text { pads }\end{array}$ \\
\hline
\end{tabular}

bridge is shown. Structural characteristics of the bridge are summarized in Table 1.

\section{Finite element model}

ABAQUS/standard version 6.7 was used to establish a 3D full-scale FE model of the RC bridge. Different types of elements were utilized to create the model. The model consisted of a concrete slab on the steel girders, which in turn were supported by capped concrete columns. Deck, girders, cap, and columns were modeled separately, and then assembled together. Deck, girders, and stiffeners were modeled with shell elements, and cap and columns were modeled using continuum solid elements. The resulting FE model contains 50,776 shell elements formed by 57,878 nodes, of which 11,016 elements were used for the deck slab and 24,736 elements were needed to model girders. Also, 15,024 solid elements were used in the model containing 19,502 nodes.

The base of bridge columns and both ends of the deck columns were hinged. The bearings were modeled as nodes between girder and pier cap. These nodes were free to rotate about deck's transverse direction and fixed in translation in other directions. A view of meshed model is displayed in Fig. 4.

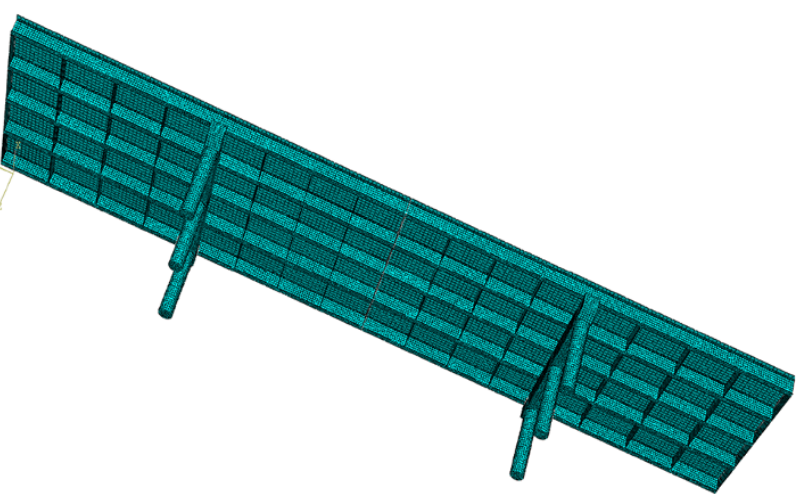

Fig. 4 The completed FE model of the bridge

Ninety-five constraints were employed to constrain top flange of the girders to the deck and connective nodes between girders and cap to simulate the action of the bearing devices.

\section{Load-time history}

Length of the bridge was $170 \mathrm{ft}$; therefore, total traveling time of the truck to cross the bridge was $12.51,6.26$, and $4.17 \mathrm{~s}$ at speeds of 10,20 , and $30 \mathrm{mph}$, respectively. To observe the possible peak response of the bridge during free vibration, the analyses were continued up to $14,8.5$ and $6.5 \mathrm{~s}$ for three load cases, respectively.

Figure 5 shows the load-time history diagram for 6-kip axles while passing the bridge. For another axle the shape of the diagrams was the same, but there was a time lag between two axles.

The influence of the moving load between two sequence nodes was calculated at ten time steps, and applied on those two nodes. Thus, if a wheel is exactly positioned on a node the next node will not feel any load. However, at the middle of the span between two sequent nodes, the effect of the wheel load on both nodes is same. Typical influence line between two sequent nodes for axle load of 6 kips is shown in Fig. 6.

In the load-time history, since the distance between two sequence nodes is roughly $60 \mathrm{in}$. (5 ft) and the distance between two axles of the trucks are $168 \mathrm{in.}(14 \mathrm{ft})$, any nodes will not be subjected to loads from two axles at the same time. As a result, the loads from two axles of the truck do not have to be superimposed.

\section{Moving load analysis}

A modal analysis followed by implicit dynamic analysis was conducted for the moving load analysis. Based on first 


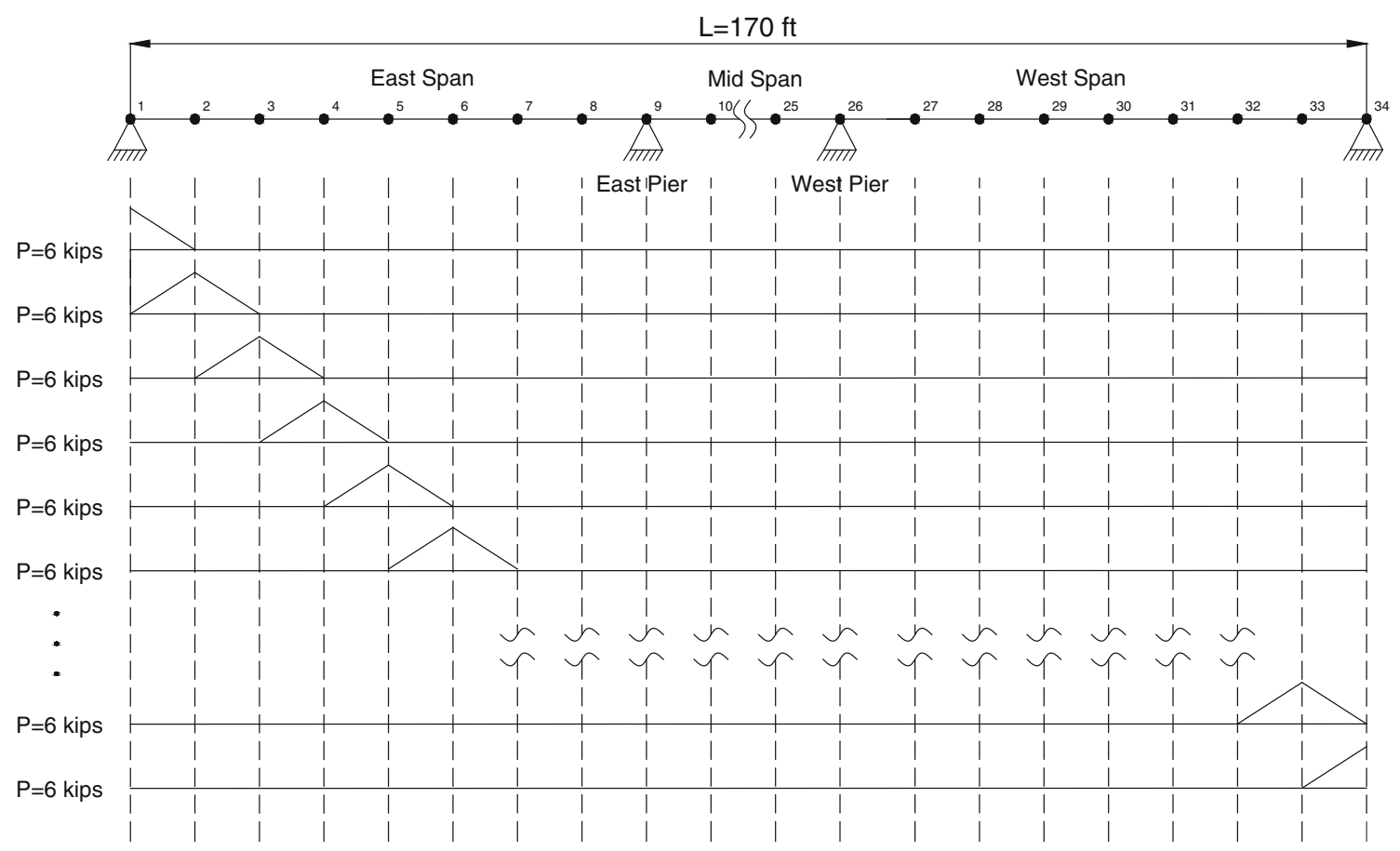

Fig. 5 Loading time history diagram for 6-kip axles (Zanjanizadeh 2009)

Fig. 6 Typical influence line between two sequence nodes for 6-kip axles

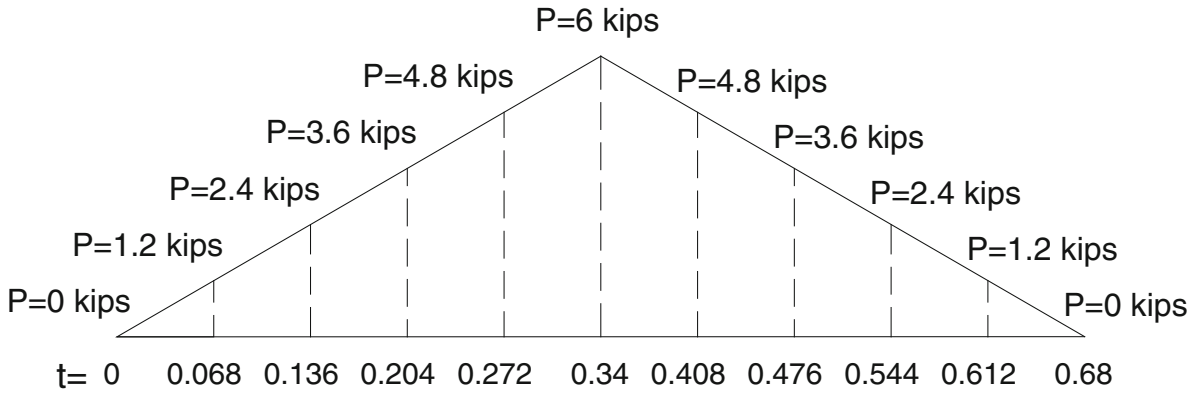

natural frequency, the substep for implicit dynamic analysis can be obtained.

Direct-integration dynamic procedure in ABAQUS/ Standard is provided using the implicit Hilber-HughesTaylor (HHT) operator for integration of the equations of motion. In an implicit dynamic analysis, a set of nonlinear equilibrium equations must be solved at each time increment followed by the integration operator matrix must be inverted. The implicit operator can be unconditionally stable and thus, there is no limit on the size of the time increment that can be used for most analyses. In fact, the time increment size is controlled only by solution accuracy.

Provided that the FE approach is linear, the equations of motion assume the form (Chopra 2011).

$M \ddot{X}+C \dot{X}+K X=F(t)$

Consider the bridge model has $n$ degree of freedom. Mass, damping, and stiffness matrices are represented by $M_{(n \times n)}, C_{(n \times n)}$, and $K_{(n \times n)}$, respectively. $X$ is the set of generalized coordinates used to represent the configuration of the system. In addition, $F$ is $n \times 1$ force vector which depends on the time.

One of the originators of the HHT scheme is the Newmark method. HHT integration formulas depend on two parameters, $\beta$ and $\gamma$ as defined below:

$X_{n+1}=X_{n}+h \dot{X} n+\frac{h^{2}}{2}\left[(1-2 \beta) \ddot{X}_{n}+2 \beta \ddot{X} n+1\right]$

$\dot{X}_{n+1}=\dot{X}_{n}+h\left[(1-\gamma) \ddot{X}_{n}+\gamma \ddot{X}_{n+1}\right]$

where $\gamma$ and $\beta$ are defined as

$\gamma \geq 1 / 2 \quad \beta \geq \frac{(\gamma+1 / 2)^{2}}{4}$

where $h$ is the integration size. Equations (2) and (3) are used to discretize equation of motion (1) at time $t_{n+1}$, therefore Eq. (1) will be transformed to 
$M \ddot{X}_{n+1}+C \dot{X}_{n+1}+K X_{n+1}=F_{n+1}$

Based on Eqs. (2) and (3), $X_{n+1}$ and $\dot{X}_{n+1}$ are function of acceleration $\ddot{X}_{n+1}$, which is only unknown quantity in Eq. (5).

The sole combination of $\beta$ and $\gamma$ that leads to a secondorder integration formula is $\gamma=1 / 2$ and $\beta=1 / 4$. However, a disadvantage of the Newmark integration method is that it is not able to provide A-stable second order and desirable level of damping. But HHT scheme eliminates this drawback since it maintains the A-stability and numerical damping properties at the same time achieving second-order accuracy when it is united with second-order linear ODE problem of Eq. (1).

$$
\begin{aligned}
& M \ddot{X}_{n+1}(1+\alpha) C \dot{X}_{n+1}-\alpha C \dot{X}_{n}+(1+\alpha) K X_{n+1}-\alpha K X_{n} \\
& \quad=F\left(\tilde{t}_{n+1}\right)
\end{aligned}
$$

where

$\tilde{t}_{n+1}=t_{n}+(1+\alpha) h$

Hence, the HHT method will possess the stability and order properties provided $\alpha \varepsilon[-1 / 3,0]$ and

$\gamma=\frac{1-2 \alpha}{2}, \quad \beta=\frac{(1-\alpha)^{2}}{4}$

These relations provide control of the numerical damping associated with the time integrator while preserving desirable characteristics of the integrator. The numerical damping grows with the ratio of the time increment to the period of vibration of a mode. The smaller the value of $\alpha$, the more damping is induced in the numerical solution; while $\alpha=0$ demonstrates trapezoidal scheme without any damping.

\section{Parametric study}

There are several important parameters in moving load analysis, which affect the dynamic response of bridges, such as material properties, speed of vehicle, damping, and vehicle weight. Studying the influence of these parameters on the bridge response theoretically provides insight into the expected response of the bridge structure and especially columns under moving loads.

Twenty-one specimens were defined to investigate the influence of these parameters. Most of the specimens were those in which the modulus of elasticity was changed. Table 2 displays the specimen properties variation. Elastic modulus of deck and piers was increased and decreased gradually up to $30 \%$. Fully and partially loaded trucks were considered in the parametric study. Also, structural

\begin{tabular}{|c|c|c|c|}
\hline Specimen \# & $\begin{array}{l}\text { Deck modulus } \\
\text { of elasticity }\end{array}$ & $\begin{array}{l}\text { Pier modulus } \\
\text { of elasticity }\end{array}$ & $\begin{array}{l}\text { Truck } \\
\text { speed } \\
(\mathrm{mph})\end{array}$ \\
\hline SP-0 & $E_{\mathrm{D}}$ & $E_{\mathrm{p}}$ & 10 \\
\hline SP-1 & $E_{\mathrm{D}}+10 \% E_{\mathrm{D}}$ & $E_{\mathrm{p}}$ & \\
\hline SP-2 & $E_{\mathrm{D}}+20 \% E_{\mathrm{D}}$ & $E_{\mathrm{p}}$ & \\
\hline SP-3 & $E_{\mathrm{D}}+30 \% E_{\mathrm{D}}$ & $E_{\mathrm{p}}$ & \\
\hline SP-4 & $E_{\mathrm{D}}$ & $E_{\mathrm{p}}+10 \% E_{\mathrm{p}}$ & \\
\hline SP-5 & $E_{\mathrm{D}}$ & $E_{\mathrm{p}}+20 \% E_{\mathrm{p}}$ & \\
\hline SP-6 & $E_{\mathrm{D}}$ & $E_{\mathrm{p}}+30 \% E_{\mathrm{p}}$ & \\
\hline SP-7 & $E_{\mathrm{D}}-10 \% E_{\mathrm{D}}$ & $E_{\mathrm{p}}$ & \\
\hline SP-8 & $E_{\mathrm{D}}-20 \% E_{\mathrm{D}}$ & $E_{\mathrm{p}}$ & \\
\hline SP-9 & $E_{\mathrm{D}}-30 \% E_{\mathrm{D}}$ & $E_{\mathrm{p}}$ & \\
\hline SP-10 & $E_{\mathrm{D}}$ & $E_{\mathrm{p}}-10 \% E_{\mathrm{p}}$ & \\
\hline SP-11 & $E_{\mathrm{D}}$ & $E_{\mathrm{p}}-20 \% E_{\mathrm{p}}$ & \\
\hline SP-12 & $E_{\mathrm{D}}$ & $E_{\mathrm{p}}-30 \% E_{\mathrm{p}}$ & \\
\hline SP-13 & $E_{\mathrm{D}}+9 \% E_{\mathrm{D}}$ & $E_{\mathrm{p}}+9 \% E_{\mathrm{p}}$ & \\
\hline SP-14 (H20-44 truck) & $E_{\mathrm{D}}$ & $E_{\mathrm{p}}$ & \\
\hline SP-15 (2 \% damping ratio) & $E_{\mathrm{D}}$ & $E_{\mathrm{p}}$ & \\
\hline SP-16 (2 \% damping ratio) & $E_{\mathrm{D}}+9 \% E_{\mathrm{D}}$ & $E_{\mathrm{p}}+9 \% E_{\mathrm{p}}$ & \\
\hline $\begin{array}{l}\text { SP-17 (partially loaded } \\
\text { H15-44 truck) }\end{array}$ & $E_{\mathrm{D}}$ & $E_{\mathrm{p}}$ & \\
\hline SP-18 (5\% damping ratio) & $E_{\mathrm{D}}+9 \% E_{\mathrm{D}}$ & $E_{\mathrm{p}}+9 \% E_{\mathrm{p}}$ & \\
\hline SP-19 & $E_{\mathrm{D}}$ & $E_{\mathrm{p}}$ & 20 \\
\hline SP-20 & $E_{\mathrm{D}}$ & $E_{\mathrm{p}}$ & 30 \\
\hline
\end{tabular}

Table 2 Specimens' properties

damping ratio and truck speeds were increased from 0 to $5 \%$ and 10 to $30 \mathrm{mph}$, respectively. The variation of each parameter is explained in following sections.

Vehicle speed variation

Vehicle speed increased from 10 to $30 \mathrm{mph}$ to investigate the effect of vehicle speed on dynamic behavior of the bridge. The objective of this parametric investigation is to find out how much the speed of vehicle can amplify the different responses of the bridge. Three different speeds $(10,20$, and $30 \mathrm{mph})$ were studied.

Modulus of elasticity variation

In some analyses, the modulus of elasticity of the deck and piers was changed to examine the effect of different modulus of elasticity variation on the dynamic response of the bridge. Increasing the modulus of elasticity represents the increase in the concrete strength because of concrete aging or underestimation of the modulus by the current ACI equation (ACI 2014). However, the decrease in modulus of elasticity signifies unexpected damage such as cracking, spalling or under-strength concrete. The aim of 
this parametric study was to look into the effect of any damage or aging of concrete, especially in the columns, on dynamic response of the bridge.

In a linear FE analysis, the modulus of elasticity affects both stiffness of the structure and stress tensor. If the modulus of elasticity of whole structure is changed uniformly, the member stiffness and stress will only be marginally changed linearly. However, if only modulus of elasticity in some parts of structure is changed, the relationship among stiffness, strain and modulus of elasticity will not be changed linearly. The linear 3-D FE formulas for a beam element are as follows (Zienkiewicz and Taylor 2013):

Shape function: $N(x, y)=\left(N_{1}, N_{2}\right)$

Element matrices $\left[k^{e}\right]=\int_{v_{e}}[B]^{T}[D][B] \mathrm{d} v$

Global stiffness matrices of structure: $[K]$

Strain: $\varepsilon=\frac{\mathrm{d} u}{\mathrm{~d} x}=\int_{v_{e}}[B]\left\{u_{e}\right\} \mathrm{d} v$

Stress: $\sigma=\int_{v_{e}}[D][B]\left\{u_{e}\right\} \mathrm{d} v$

By changing the modulus of elasticity $(E)$ either $[D]$ matrix or the stress tensor matrix will be changed. As a consequence, the element stiffness matrix is going to be amended; the dynamic response and strain of the structure will be altered. Since in these analyses only modulus of elasticity of the deck or piers was varied, predicting strain and stress by hand calculation is almost impossible, and a computer-based FE modeling should be implemented to get any meaningful output.

\section{Damping variation}

Damping in RC bridges is a complex phenomenon, and its precise description and representation in a FE model are difficult. Generally, damping depends on the material and the condition of the bridge (presence of cracks, connections), as well as the amplitude and frequency of vibrations. However, the frequency has rather insignificant influence on damping in the range up to $50 \mathrm{~Hz}$, which usually covers the most common natural frequencies of highway bridges. Considering this point, damping in bridges is well described by structural damping theory in the range of linear material deformations. SP-13, SP-15, SP-16, and SP-18 were those analyses in which the damping was varied to examine the effect of damping on dynamic response of the bridge.
Table $3 \alpha$ and $\beta$ values for damping ratios of 2 and $5 \%$

\begin{tabular}{lll}
\hline $\begin{array}{l}\xi \text { (damping } \\
\text { ratio) }\end{array}$ & $\alpha$ & $\beta$ \\
\hline $2 \%$ & 0.00581 & 0.0549 \\
$5 \%$ & 0.01452 & 0.1373 \\
\hline
\end{tabular}

Rayleigh damping was utilized to consider the structural damping mechanisms in the dynamic analysis of the bridge. The Rayleigh damping is combination of two parts: mass-proportional damping and stiffness proportional damping as follows (Chopra 2011):

$[C]=\alpha[m]+\beta[k]$

The damping ratio for the $n$th mode of the system is

$\xi_{n}=\frac{\alpha}{2} \frac{1}{\omega_{n}}+\frac{\beta}{2} \omega_{n}$

The coefficient $\alpha$ and $\beta$ can be determined from certain damping ratios $\zeta_{\mathrm{i}}$ and $\zeta_{\mathrm{j}}$ for $i$ and $j$ modes, respectively. Equation (13) can be rewritten in the matrix form as below:

$\frac{1}{2}\left[\begin{array}{ll}1 / \omega_{i} & \omega_{i} \\ 1 / \omega j & \omega_{j}\end{array}\right]\left\{\begin{array}{l}\alpha \\ \beta\end{array}\right\}=\left\{\begin{array}{l}\xi_{i} \\ \xi_{j}\end{array}\right\}$

when $\xi_{\mathrm{i}}=\xi_{\mathrm{j}}$, by solving Eq. (15) in terms of $\xi_{\mathrm{i}}$ and $\xi_{\mathrm{j}}, \alpha$ and $\beta$ can be obtained as shown below:

$\alpha=\xi \frac{2 \omega_{i} \omega_{j}}{\omega_{i}+\omega_{j}}, \quad \beta=\xi \frac{2}{\omega_{i}+\omega_{j}}$

To determine $\alpha$ and $\beta$ the appropriate damping ratio is required. The $\xi=2 \%$ and $\xi=5 \%$ of damping ratios were assumed in the parametric study. Two first dominant modes which have characteristics of the vertical deformation of the bridge are mode 1 and mode 5 with corresponding frequencies of 0.20 and 0.53 , respectively. Calculated values for $\alpha$ and $\beta$ are shown in Table 3. These values are equivalent to 2 and $5 \%$ of damping ratios in dynamic analysis in ABAQUS.

Truck weight variation

The weight of the vehicle is one of the parameters that can affect the response of the bridge directly. Especially when the load is dynamic, the response can be amplified with respect to static loads. Three different truck loads were employed to examine this parameter; partially (83\%) loaded HS15-44 truck (SP-17), fully loaded H15-44 truck (SP-0), and fully loaded HS20-44 truck (SP-14). SP-0, SP14 , and SP-17 have properties of such weights. All the trucks represent a class- $\mathrm{V}$ vehicle (according to AASHTO) with one rear and one front axle. The distance between axles is $14 \mathrm{ft}$. H20-44 truck has rear axle load of 32 kips and front axle load of 8 kips. H15-44 truck has rear axle 
Fig. 7 First 6 mode shapes and corresponding frequencies (vertical displacement; red is positive and blue is negative)

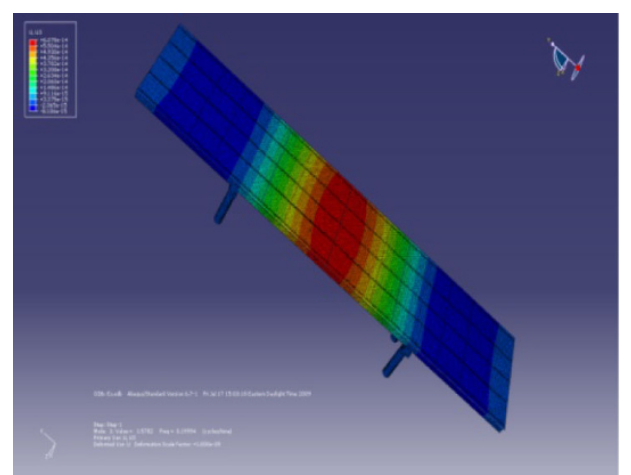

Mode1-Freq.: 0.200

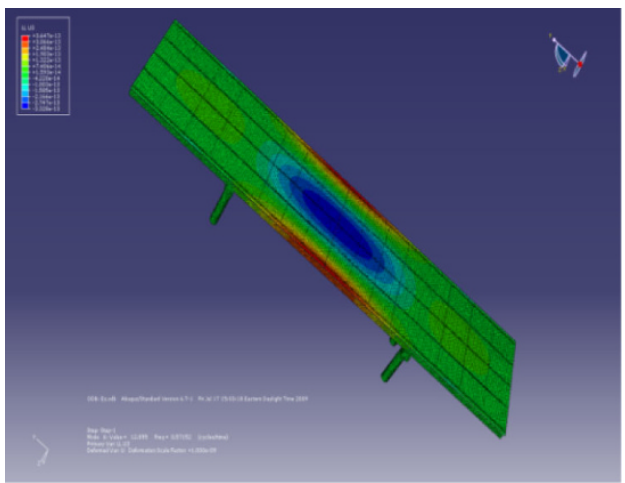

Mode3-Freq.:0.224

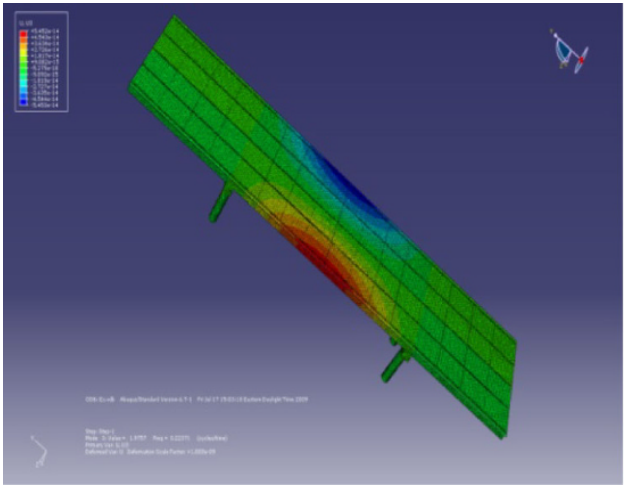

Mode5-Freq.: 0.529

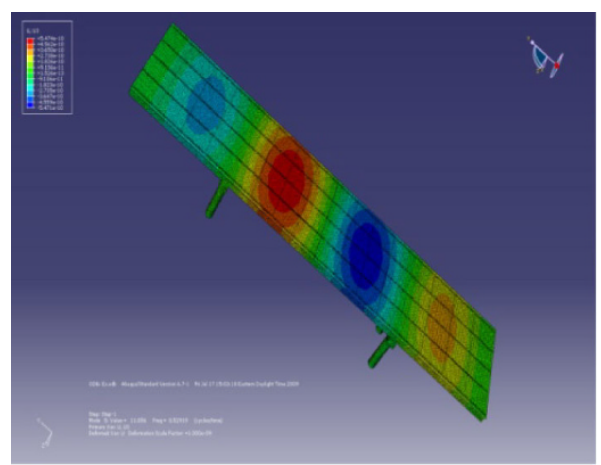

Mode2-Freq.:0.205

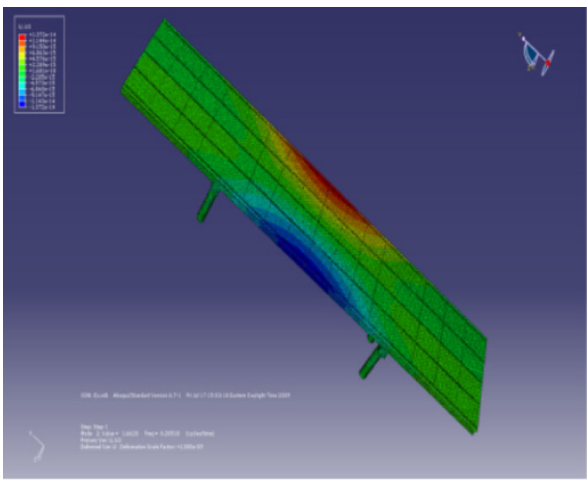

Mode4-Freq.:0.388

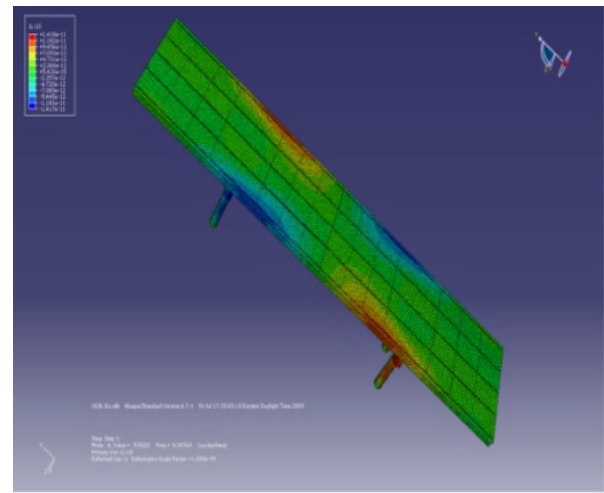

Mode6-Freq.: 0.572 load of 24 kips and front axle load of 6 kips; whereas, the partially loaded H15-44 truck has rear axle load of 20 kips and front axle load of 5 kips.

\section{Discussion and results}

In this section, the results of the modal and implicit dynamic analyses are discussed. After illustrating the natural modes of the bridge, and validating the results with the field test data, the effect of four parameters on moving load analysis and bridge column response will be discussed. The studied parameters were speed of the truck, modulus of elasticity, damping ratio, and truck weight.

\section{Modal analysis}

First 30 natural modes of the bridge were extracted. First six modes and associated frequencies are shown in Fig. 7. First frequency was used in determining the substep in implicit dynamic analysis. To capture the accurate response of the bridge, the substep size was set to be smaller than first natural frequency of the bridge. 
Selected locations to obtain the results

Several nodes and elements were chosen to acquire the results from output database. Some output variables were recorded from the nodes and some of them from the elements. Strains and stresses were extracted using Gaussian quadrature rule which gives high-order accuracy with very few points. Table 4 presents the particular points and nodes which were used in evaluating the results.

Validating of the finite element modeling with experimental study

Over the years, dynamic tests and SHM of bridges have been investigated by many researchers and engineers. Experiments on a structure allow an analyst to validate results generated using a FE model (or other analytical or numerical methods), and as a result, confidence could be placed on the structural model to provide meaningful analysis results.

In this study, to validate the FE outputs, a field test from Farhey (2006) was used. The bridge that was modeled in this study was the same as the one described by Farhey (2006), and the structural details were obtained from Ohio Department of Transportation (ODOT). The objective of the experimental study by Farhey (2006) was to develop a rapid response, computer-controlled field laboratory system, integrating virtual instrumentation with multiple-channel wireless site network for SHM. They used a single-axle, 25-kip $(110-\mathrm{kN})$ loaded truck for the test. The front axle load is 5 kips and the rear one is loaded 20 kips.

In the FE modeling, SP-13 is the analysis with the same vehicle passing through the same lane as in experimental study. In this analysis, the aging of the concrete was taken

Table 4 Particular points used in obtaining results

\begin{tabular}{lll}
\hline Name & Location & Output \\
\hline CLF1 & $\begin{array}{c}\text { Element at middle of the column } \\
\text { located at north-west of the bridge } \\
\text { CRF1 }\end{array}$ & $\begin{array}{c}\text { Average of element } \\
\text { integration points } \\
\text { located at north-east }\end{array}$ \\
GML2 & $\begin{array}{c}\text { Element on the girder at right side of } \\
\text { the middle span, second beam from } \\
\text { north }\end{array}$ & $\begin{array}{c}\text { Average of element } \\
\text { integration points } \\
\text { integration points }\end{array}$ \\
RL1 & $\begin{array}{c}\text { Base of first column at north-west of } \\
\text { the bridge }\end{array}$ & $\begin{array}{c}\text { Sum-up of the } \\
\text { reaction nodes }\end{array}$ \\
RF1 & $\begin{array}{c}\text { Node at middle of the cross-section } \\
\text { of a column located at north-east }\end{array}$ & $\begin{array}{c}\text { Node } \\
\text { VP1 }\end{array}$ \\
$\begin{array}{c}\text { Bottom flange of the beam 2 from } \\
\text { north side, on E-pier }\end{array}$ & $\begin{array}{c}\text { Average of element } \\
\text { integration points }\end{array}$ \\
VP2 & $\begin{array}{c}\text { Bottom flange of beam 2, north side } \\
\text { E-span }\end{array}$ & $\begin{array}{c}\text { Average of element } \\
\text { integration points }\end{array}$ \\
& $\quad$
\end{tabular}

into account to match with the material properties at the time of the field experiment.

The parameters that were chosen for verification were (1) the tension strains in the 2-2 direction at the bottom of girder- 2 on north side and east span, and (2) on the same beam and same side but this time over the east pier. The strains obtained from experiment and FE modeling were consistent and are displayed in Figs. 8 and 9, respectively. The difference between the field test and FE modeling results can be attributed to lack of information and assumptions over the test, because exact location of the sensors is not given in the reference.

\section{Effect of truck speed}

It is recognized that as the speed of the vehicle increases, a significant increase in the vibration acceleration is induced. Even though it is affected by roughness of the deck slab, larger responses are expected by increasing the vehicle speed. Three vehicle speeds were studied including 10, 20, and $30 \mathrm{mph}$, and strains in selected spots on the columns and girders, and also reaction force of an external column were extracted for comparison.

Figure 10 shows the strains in 3-3 direction at CLF1 for SP-0, SP-19, and SP-20. The curves demonstrate that the strain rate in the column increased as the speed of truck increased. At nearly $4 \mathrm{~s}$, the increase for speed of $30 \mathrm{mph}$ reached up to $80 \%$ more than its counterpart for speed of $20 \mathrm{mph}$. This graph demonstrates the large effect of the truck speed on strains in the columns. Figure 11 depicts strain in 3-3 direction at CRF1 for SP-0, SP-19, and SP-20. The figure indicates considerable effect of truck speed variation on strain in the columns. Brady et al. (2006) also showed large effect of truck speed on dynamic response of the bridges. Figure 12 shows exaggerated vertical deformation at time $=2.67 \mathrm{~s}$ for SP-19.

\section{Modulus of elasticity variation effect}

Thirteen analyses were defined to study modulus of elasticity effect that signifies damage or aging of concrete. The relevant graphs are shown in Figs. 13 and 14. It was observed from the graphs that the strains at 3-3 direction in the column increased up to $40 \%$ when the modulus of elasticity of the columns decreased by $30 \%$. However, the modulus of elasticity reduction of deck did not have that much effect on the strains in the columns and girders. This means the influence of piers is more dominant in dynamic behavior of the bridge. Natural frequencies of SP-0 to SP12 are shown in Fig. 15. The natural frequencies of the analyses with pier elastic modulus variation (SP-4, SP-5, SP-6, SP-10, SP-11, SP-12) also emphasize the importance of the piers on overall dynamic behavior of the bridges. For 
Fig. 8 Strain history from conventional monitoring system (Reproduced with Permission of Sage Publications from Farhey 2006)

Fig. 9 Strain history from FE analysis

Fig. 10 Strain in 3-3 direction at CLF1 for SP-0, SP-19, and SP-20
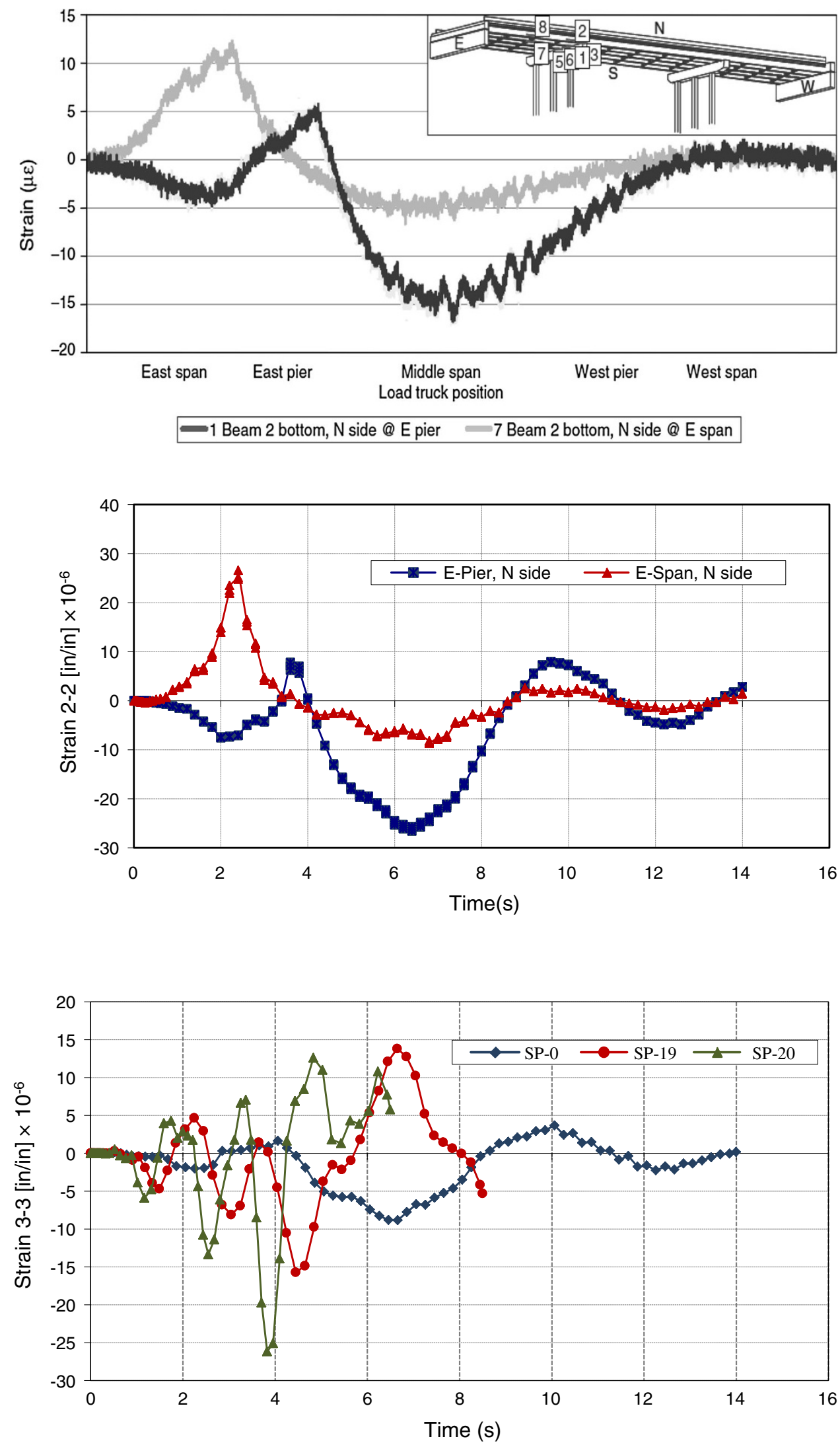
Fig. 11 Strain in 3-3 direction at CRF1 for SP-0, SP-19, and SP-20

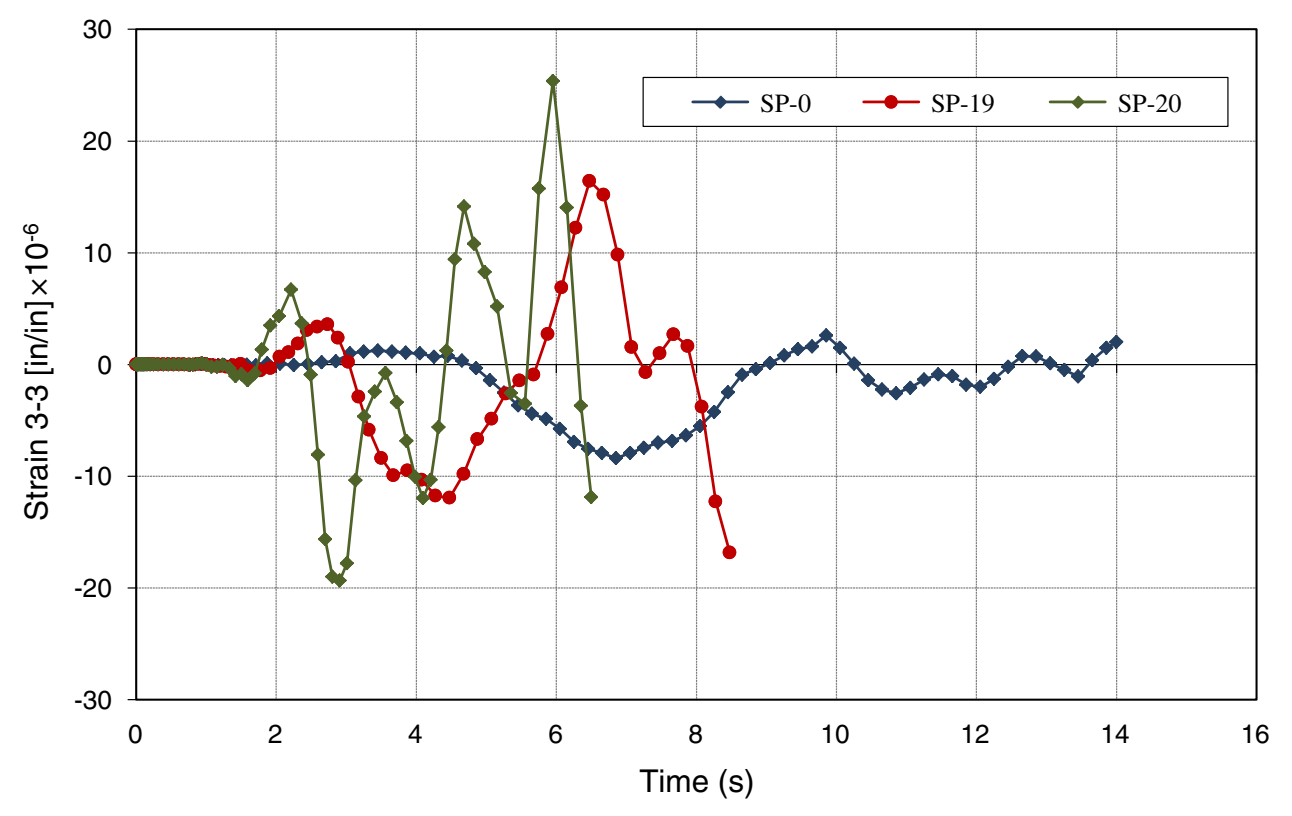

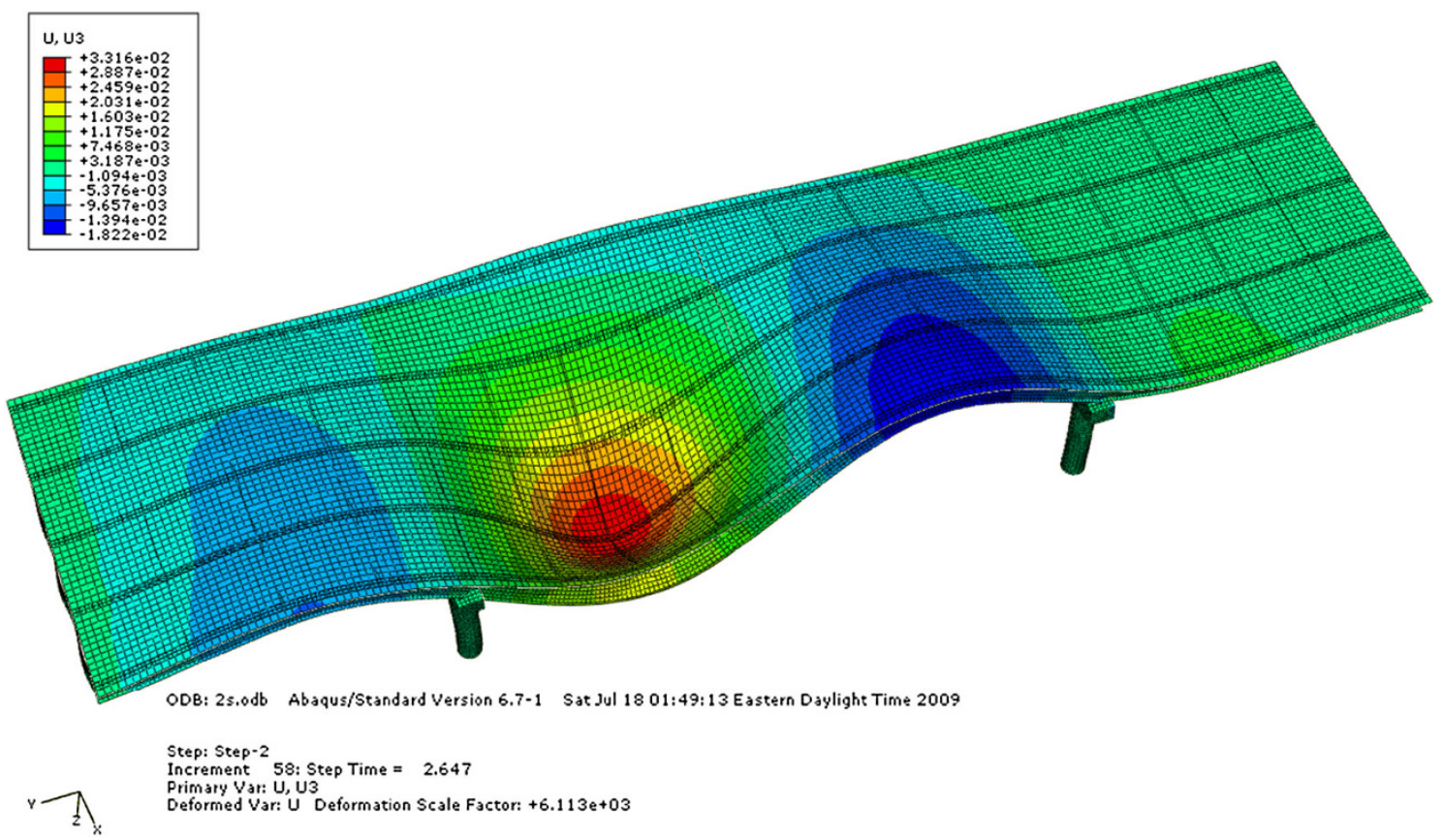

Fig. 12 Exaggerated vertical deformation at time $=2.67 \mathrm{~s}$ for SP-19

example, by reducing elastic modulus of piers by $30 \%$, the first natural frequency of the bridge was decreased about $25 \%$.

\section{Damping effect}

Since the damping in concrete structures is a complex parameter, broad evaluation of bridge condition is needed to estimate the damping effect. For simplification in this study, two reasonable values, 2 and $5 \%$ damping ratios were included in four analyses to evaluate the effect of damping on the bridge response. Figure 16 illustrates the strain in 2-2 direction in two different locations (VP1 and VP2) for three analyses. The SP-16 has $5 \%$ damping ratio, the SP-18 has $2 \%$, and there is no damping in SP-13. It is comprehensible from the graph that by increasing the damping ratios the strain on the girders was decreased insignificantly, and shape of the response curves stayed the same. Damping ratio variation had a minor effect on overall response of the bridge. The influence of damping in free vibration was greater than the time when the loading is applied. In 
Fig. 13 Strain in 3-3 direction at CLF1 for the runs from SP-0 to SP-6

Fig. 14 Strain in 3-3 direction at CLF1 for the runs from SP-7 to SP-12 and SP-0
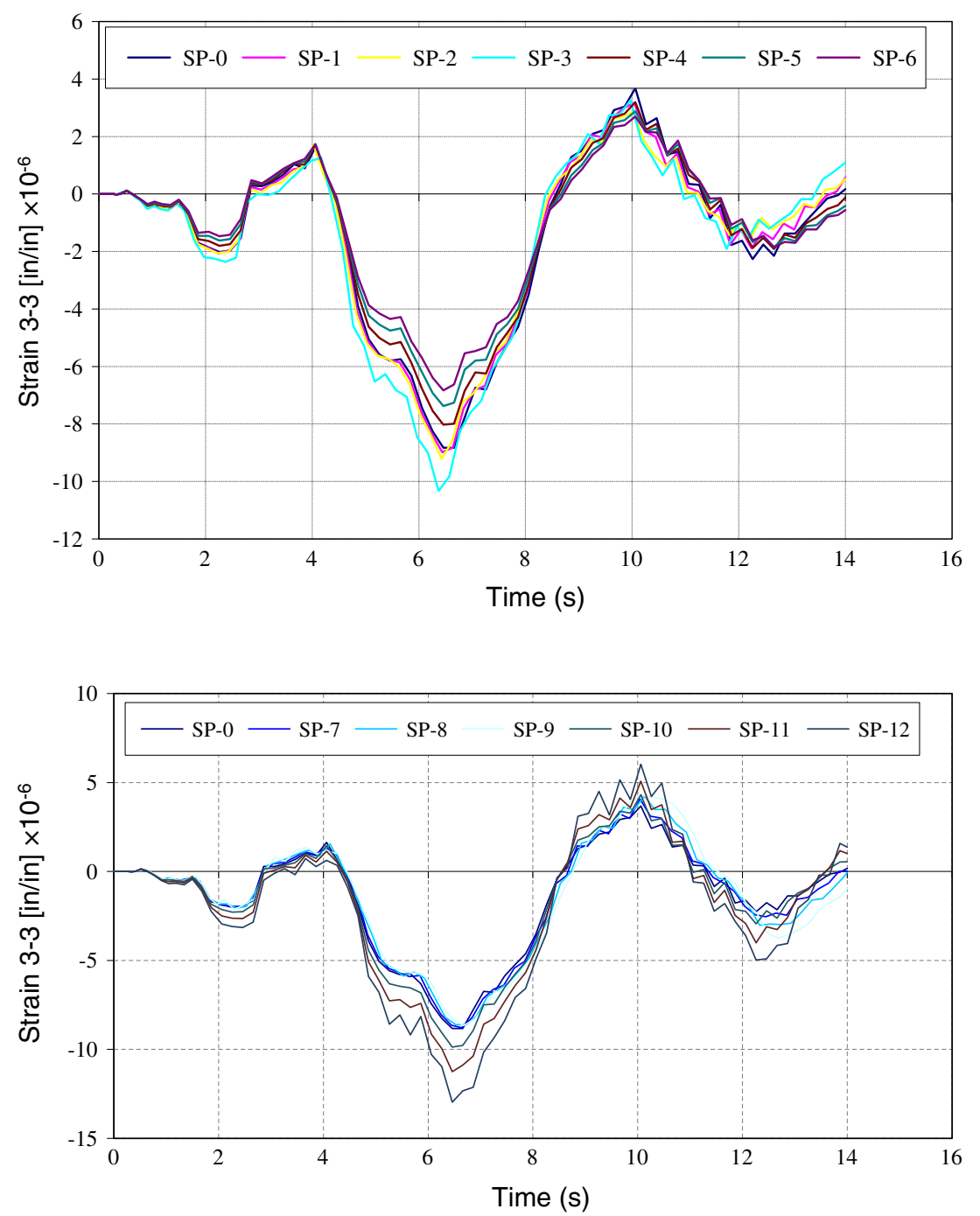

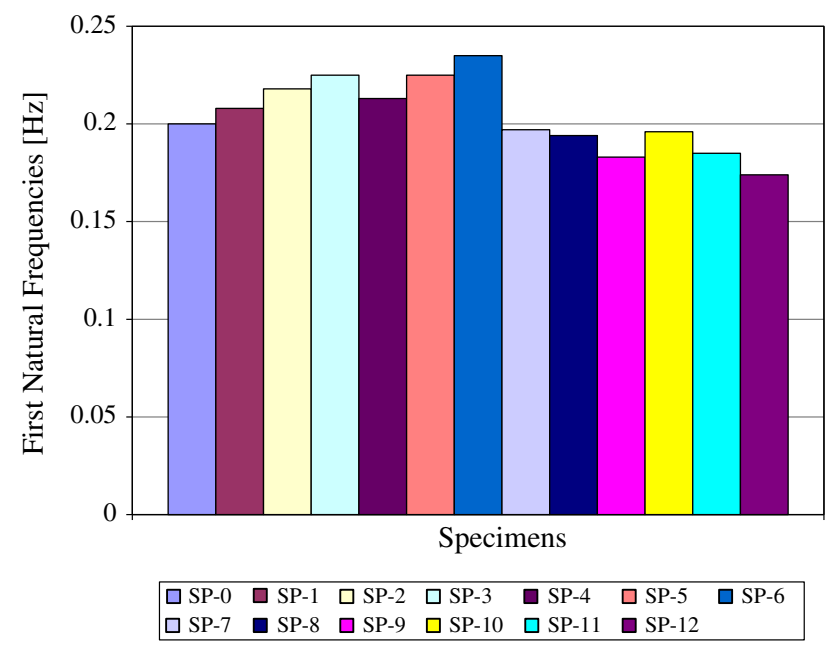

Fig. 15 First natural frequency of the runs from SP-0 to SP-12

addition, its effect is noticeable in the high-frequency vibration rather than general response. This effect caused smoothing the response curves.
Truck weight effect

Three analyses (SP-0, SP-14, SP-17) were defined to investigate the influence of the truck weight. The following four plots in Figs. 17, 18, 19, and 20 show the variation of the bridge responses with varying vehicle weight. All four diagrams show that the response of the vehicle increases as the vehicle weight increases. The highest increase was observed in the case of strain response on the columns and girders. As presented in Fig. 17, truck H20-44 caused roughly $30 \%$ more strain in CLF1 compared to truck H15-44. The increase is around $40 \%$ compared with the partially loaded H15-44 truck (SP-17). This can be due to static load effect rather than dynamic effect of applied loading (Paultre et al. 1992).

Figure 18 displays the strain at GML2 in 2-2 direction for SP-0, SP-14, and SP-17. Similar to previous plots, the figure shows that the strain at GML2 was increased as the vehicle load is increased. However, the amount of increase for acceleration response is greater than others as it is revealed in Fig. 20. 
Fig. 16 Strain at VP1 and VP2 for SP-13, SP-16, and SP-18

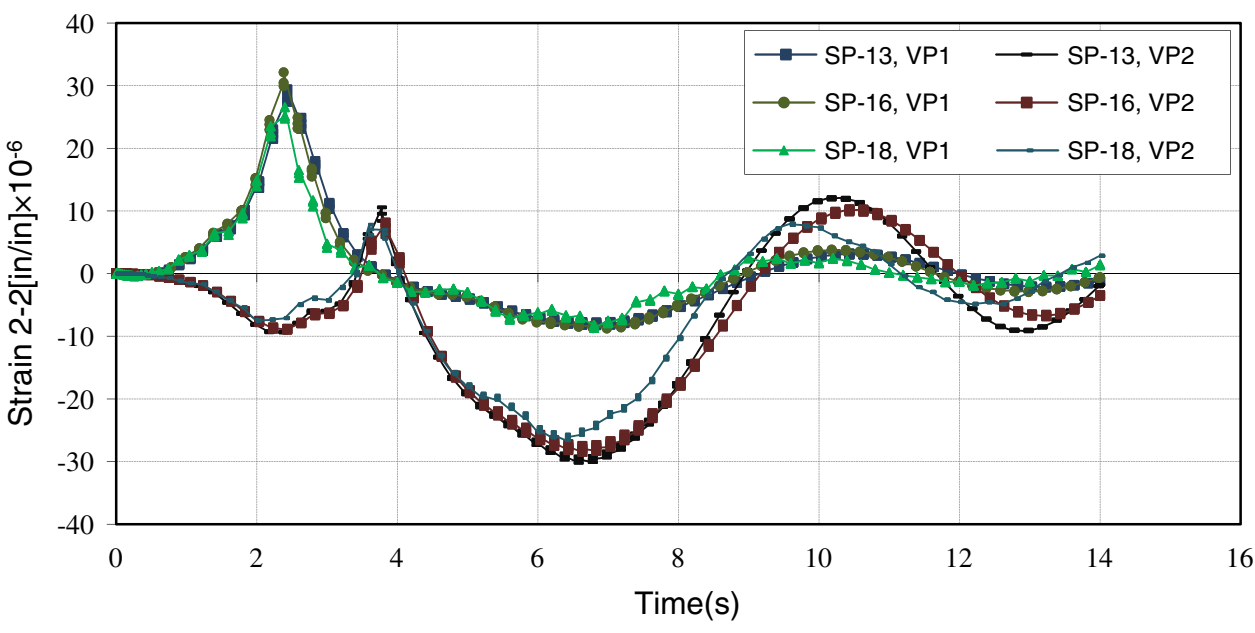

Fig. 17 Strain at CLF1 in 3-3 direction for SP-0, SP-14, and SP-17

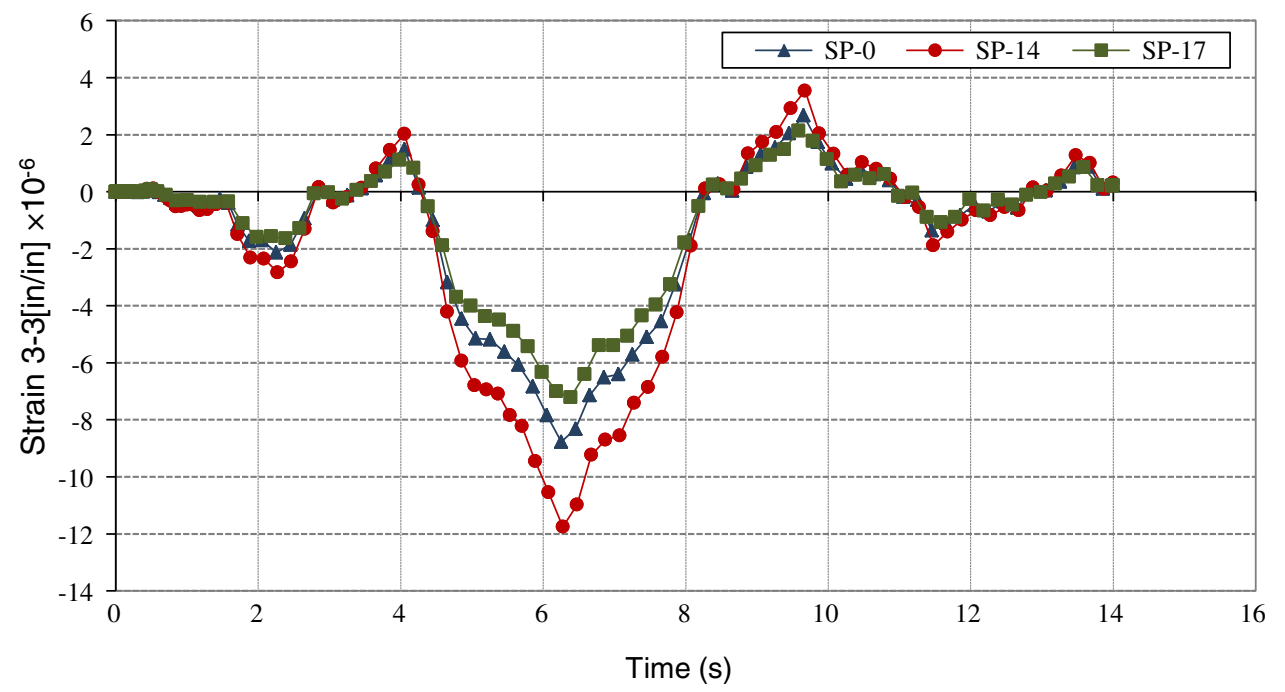

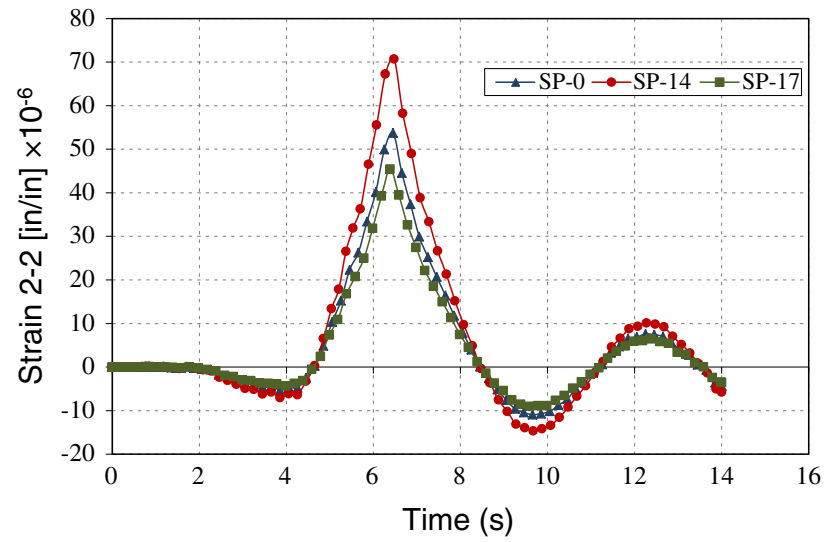

Fig. 18 Strain at GML2 in 2-2 direction for SP-0, SP-14, and SP-17

\section{Conclusion}

The most important result from this research is acceptable matching of the results of field test measurement and FE model with prescribed loading history. The range of the strains obtained from the FE modeling did not exceed $100 \mathrm{E}-6$ for columns, even for a truck speed of $30 \mathrm{mph}$. Hence, we can expect the sensors used in a SHM project to record strains between 0 and $100 \mathrm{E}-6$. This value is much less than the normally expected sensor sensitivity (2000E-6).

The following specific conclusions may be drawn from this research:

1. The study revealed that through complex FE modeling of the entire bridge structure in ABAQUS/Standard, a greater understanding of response of bridges due to moving loads can be obtained. A methodology was developed in this study to determine strains in the girders and in the piers (columns) under moving loads.

2. The dynamic response developed by FE modeling in this study compared well with the measured response of a steel girder supported composite RC deck bridge located in Ohio (USA). The range of the strains determined from the analysis was reasonably close to 
Fig. 19 Reaction force at RLF1 in 3-3 direction for SP-0, SP14 , and SP-17
Fig. 20 Acceleration component at RLF1 in 3-3 direction for SP-0, SP-14, and SP-17
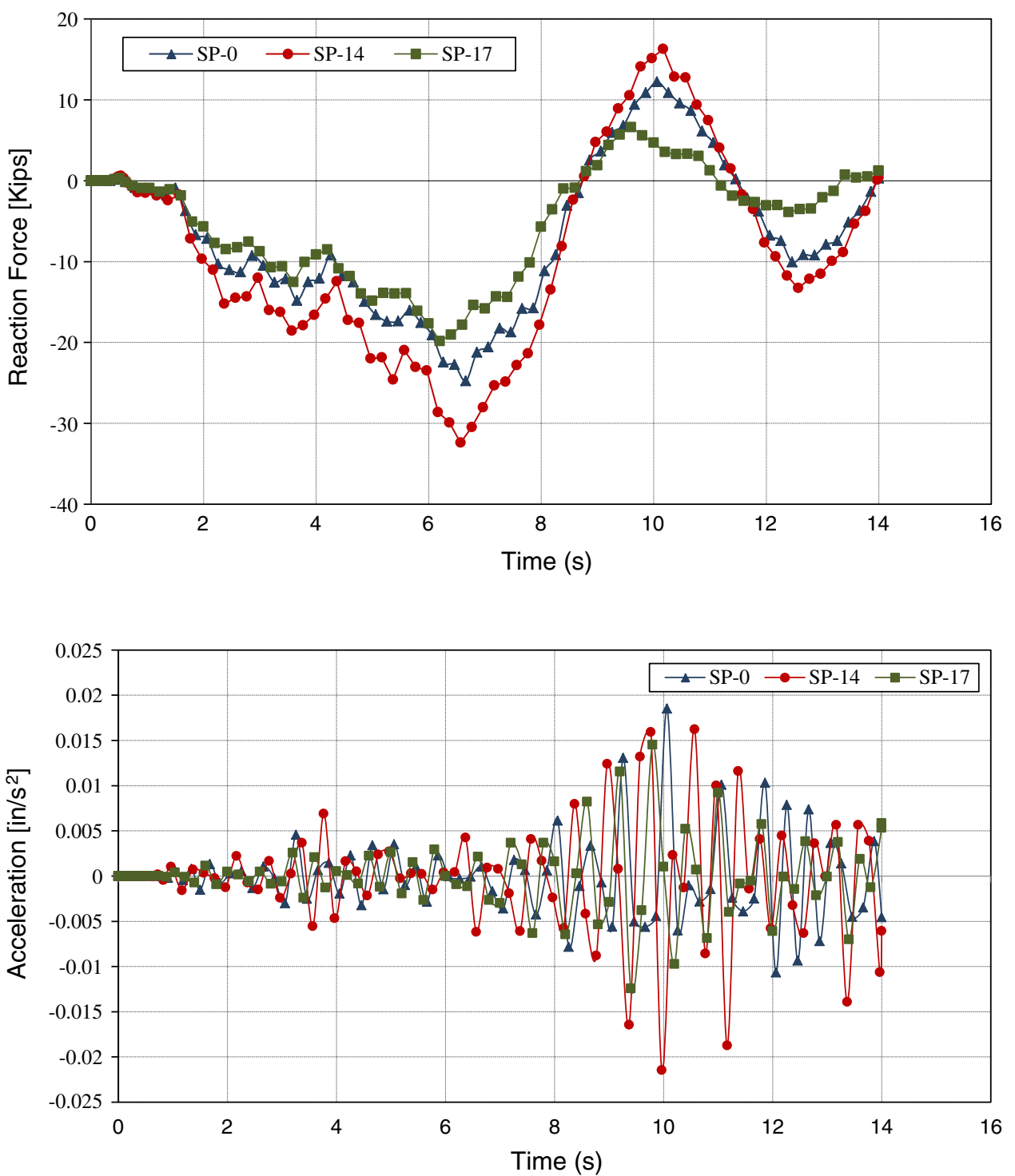

the measured strains. A better match can be achieved if the precise locations of the sensors used in the field tests are defined. However, the shape of the load-time history of strains developed by FE modeling matched perfectly with the shape of the time history of strains measured in the field test. This validated the FE analysis methodology developed in this study.

3. From the FE analysis, several parameters were determined to have an influence on dynamic responses of bridges subjected to moving vehicles. The truck speed proved to have significant effect on bridge column response. The results revealed that the strains in the bridge girders and columns increased by about $60-80 \%$ as the truck speed increases from 10 to 30 $\mathrm{mph}$. However, the truck speed did not have that much effect on the strains in 2-2 direction. Also, truck speed increased the reaction forces by $10-20 \%$.

Modulus of elasticity variation effect on the bridge response was carefully investigated. Despite the effects of the changing of modulus of elasticity being minor, the strain in entire bridge was influenced noticeably when elastic modulus of the columns was changed. Any variation in the modulus of elasticity did not have noticeable effects on the reaction forces of the bridge columns.

Damping decreased the dynamic response of the bridge. However, it influenced mostly the high-frequency modes rather than low-frequency modes.

The last parameter was the truck weight. Larger truck weight induced larger bridge response. As the truck weight 
increased by $17 \%$, the strains on the bridge columns increased by $20-25 \%$. The accelerations and strains on the girders experienced similar increases in the response.

All in all, this study demonstrated the importance of the columns and their associated strength and stiffness deterioration in SHM analysis.

Open Access This article is distributed under the terms of the Creative Commons Attribution License which permits any use, distribution, and reproduction in any medium, provided the original author(s) and the source are credited.

\section{References}

ABAQUS/Theory Manual (2007) ABAQUS/Theory Manual, Version 6.7-1, Hibbit, Karlsson and Sorensen Inc.

ACI Manual of Concrete Practice (2014), American concrete institute, Part-1

Aktan AE, Helmicki AJ, Hunt VJ (1998) Issues in health monitoring for intelligent infrastructure. Smart Mater Struct 7:674-692

American Association of State Highway and Transportation and Officials (2012) AASHTO-LRFD Bridge design specifications, 6th edn. Washington, DC

Brady SP, O'Brien EJ, Znidaric A (2006) Effect of vehicle velocity on the dynamic amplification of a vehicle crossing a simply supported bridge. J Bridge Eng 11(2):241-249

$\mathrm{Bu}$ JQ, Law SS, Zhu XQ (2006) Innovative bridge condition assessment from dynamic response of a passing vehicle. J Eng Mech ASCE 132(12):1372-1379

Cai CS, Shia XM, Araujoa M, Chenb SR (2007) Effect of approach span condition on vehicle-induced dynamic response of slab-ongirder road bridges. Eng Struct 29(12):3210-3226

Cheng YS, Au FTK, Cheung YK, Zheng DY (1999) On the separation between moving vehicles and bridges. J Sound Vib 222(5):781-801

Chiewanichakorn M, Aref AJ, Alampalli S (2007) Dynamic and fatigue response of a truss bridge with fiber reinforced polymer deck. Int J Fatigue 29:1475-1489

Cho S, Jo H, Jang S, Park J, Jung HJ, Yun CB, Spencer BF, Seo JW (2010) Structural health monitoring of a cable-stayed bridge using smart sensor technology: data analyses. Smart Struct Syst 6(5-6):461-480

Chopra AK (2011) Dynamics of structures: theory and applications to earthquake engineering, 4th edn. Prentice-Hall, New Jersey

Deng L, Cai CS (2010) Development of dynamic impact factor for performance evaluation of existing multi-girder concrete bridges. Eng Struct 32(1):21-31

El-Tawil S, Severino E, Fonseca P (2005) Vehicle collision with bridge piers. J Bridge Eng 10(3):345-353

Eshghi S, Zanjanizadeh V (2008) Retrofit of slender square concrete columns by glass fiber-reinforced polymer for seismic resistance. Iran J Sci Technol 32(B5):437-450

Eshghi S, Zanjanizadeh V (2007) Repair of earthquake-damaged square R/C columns with glass fiber-reinforced polymer. Int $\mathrm{J}$ Civil Eng 5(3):210-223

Farhey DN (2006) Integrated virtual instrumentation and wireless monitoring for infrastructure diagnostics. Struct Health Monit 5(1):29-43
Federal highway Administration (FHWA) (2008) National Bridge Inventory (NBI). http://www.fhwa.dot.gov/bridge/nbi.htm

Ganapuram S, Adams M, Patnaik A (2012) Quantification of cracks in concrete bridge decks in Ohio District 3. The University of Akron, Akron, $\mathrm{OH} 44325-2102$

Huang M, Gua W, Zhu H, Li L (2006) Dynamic test and finite element model updating of bridge structures based on ambient vibration. J Huazhong Univ Sci Technol 23(4):57-60

Kim S, Pakzad S, Culler D, Demmel J, Fenves G, Glaser S, Turon M (2007) Health monitoring of civil infrastructures using wireless sensor networks. In: 6th International Symposium on IPSN, pp 254-263. IEEE Press, New York

Kwasiewski L, Wekezer JF, Roufa G, Li H, Ducher J, Malachowski J (2006) Experimental evaluation of dynamic effects for a selected highway bridge. J Perform Constr Facil 20(3):253-260

Kwasniewskia L, Lib H, Wekezerb J, Malachowskic J (2006) Finite element analysis of vehicle-bridge interaction. Finite Elem Anal Des 42(11):950-959

Li H, Wekezer JF, Kwasniewski L (2008) Dynamic response of a highway bridge subjected to moving vehicles. J Bridge Eng 13(5):439-448

Lynch JP (2007) An overview of wireless structural health monitoring for civil structures. Phil Trans R Soc 365:345-372

Lynch JP, Sundararajan A, Law KH, Kiremidjian AS, Carryer E (2003) Power-efficient wireless structural monitoring with local data processing. In: Proceedings of the 1st International conference on structural health monitoring and intelligent infrastructure (SHMII'03), Tokyo, pp 13-15

Paultre P, Challal O, Proulx J (1992) Bridge dynamics and dynamic amplification factors - a review of analytical and experimental findings. Can J Civil Eng 19(2):260-278

Stajano F, Hoult N, Wassell I, Bennett P, Middleton C, Soga K (2010) Smart bridges, smart tunnels: transforming wireless sensor networks from research prototypes into robust engineering infrastructure. Ad Hoc Netw 8(8):872-888

Tonias DE, Zhao JJ (2012) Bridge engineering, design and rehabilitation and maintenance of modern highway bridges, 3rd edn. McGraw-Hill Education

Wang Y, Loh KJ, Lynch JP, Fraser M, La K, Elgamal A (2007) Vibration monitoring of Voigt Bridge using wired and wireless monitoring systems. The processing of 4th China-Japan-US symposium on structural control and monitoring, Hangzhou, pp 16-17

Yang YB, Chang CH, YAU JD (1999) An element for analyzing vehicle-bridge systems considering vehicle's pitching effect. Int J Numer Methods 46(7):1031-1047

Yin X, Fang Z, Cai CS, Deng L (2010a) Non-stationary random vibration of bridges under vehicles with variable speed. Eng Struct 32(8):2166-2174

Yin X, Fang Z, Cai CS (2010b) Lateral vibration of high-pier bridges under moving vehicular loads. J Bridge Eng 16(3):400-412

Yun CB, Min J (2011) Smart sensing, monitoring, and damage detection for civil infrastructures. KSCE J Civil Eng 15(1):1-14

Zanjanizadeh V (2009) Use of finite element modeling for condition assessment of reinforced concrete bridge columns in structural health monitoring. Master's Thesis, University of Akron, Akron

Zhang N, Xia H, Guo W (2008) Vehicle-bridge interaction analysis under high-speed trains. J Sound Vib 309(3-5):407-425

Zienkiewicz OC, Taylor RL (2013) The Finite Element Method, 7th edn. Butterworth Heinemann, Oxford 